\title{
A Hybrid Modulation Strategy with Reduced Switching Losses and Neutral Point Potential Balance for Three-Level NPC Inverter
}

\author{
Weidong Jiang ${ }^{\dagger}$, Yan Gao*, Jinping Wang* and Lei Wang*
}

\begin{abstract}
In this paper, carrier-based pulse width modulation (CBPWM), space vector PWM (SVPWM) and reduced switching losses PWM (RSLPWM) for the three-level neutral point clamped (NPC) inverter are introduced. In the case of the neutral point (NP) potential (NPP) offset, an asymmetric disposition PWM (ASPDPWM) strategy is proposed, which can output PWM sequences correctly and suppress the lower order harmonics of the inverter effectively. An NPP balance strategy based on carrier based PWM (CBPWM) is analyzed. A hybrid modulation strategy combining RSLPWM and the NPP balance based on CBPWM is proposed, and hysteresis control is adopted to switch between the two modulation strategies. An experimental prototype of the three-level NPC inverter is built. The effectiveness of the hybrid modulation is verified with a resistance-inductance load and a permanent magnetic synchronous motor (PMSM) load, respectively. The experimental results show that reduced switching losses and an acceptable NPP can be effectively achieved in the hybrid modulation strategy.
\end{abstract}

Keywords: Neutral point clamped, Three-level inverter, CBPWM, ASPDPWM, Neutral point potential, Switching losses, Hybrid modulation

\section{Introduction}

Multilevel inverter topologies have received special attention during the last two decades due to their significant contributions to medium/high-voltage and highpower applications [1], such as ac motor drives [2, 3], electric energy quality management and reactive power compensation $[4,5]$. Even in low-power low-voltage fields, this topology is used in more and more applications $[6,7]$.

Compared to the two-level inverters, multilevel inverters reduce the voltage stresses by each semiconductor, eliminate the problems associated with direct series interconnection of switching devices, and lower the harmonic distortion of the output voltage. However, a larger number of semiconductor devices is needed, which results in a more complex PWM strategy being required.

In order to exert the advantages of the three-level topology, the following requirements must be satisfied: (1) ensure the neutral point potential (NPP) balance; (2) reduce switching losses; (3) reduce the output harmonics as much as possible, especially for lower order harmonics.

PWM strategies for three-level voltage source inverters can be broadly categorized into carrier based PWM (CBPWM) [8-10] and space vector PWM (SVPWM) [11, 12]. Some existing literature has introduced discontinuous PWM strategy $[13,14]$. The output pulse signals are

$\dagger$ Corresponding Author: Dept. of Electrical Engineering and automation, Hefei University of technology, China. (ahjwd@163.com)

* Dept. of Electrical Engineering and automation, Hefei University of technology, China.(1060459040@qq.com, waupter919@163.com; hfutwanglei@126.com)

Received: January 19, 2016; Accepted: November 17, 2016 generated by comparing the modulated wave with the carrier under CBPWM; SVPWM calculates the application time of every basic space voltage vector, and then the pulse signals are output in a predetermined order. Injecting proper common-mode voltage (CMV) can achieve the equivalent between CBPWM and SVPWM [15]. Compared with SVPWM, CBPWM is easier to implement.

Unbalanced DC-link voltage will affect the normal operation of the inverter. In order to exert the advantages of the topology, the voltages of the upper and lower capacitors must be confined to half of the DC-link voltage. The available methods for NPP balance in the existing literature can be classified as follows.

(1) Add extra hardware circuitry to balance the NPP [16, 17], by controlling the change rate of the charging and discharging currents of the upper and lower capacitors. The control method, depending on the hardware circuitry, will increase system costs, and become more complicated.

(2) Ameliorate the control strategy based on CBPWM and SVPWM [18-23].

Each of the aforementioned studies tries to control the charging and discharging of the capacitors such that the NPP is balanced. By adopting CBPWM, three different methods are designed to balance the NPP by common mode voltage (CMV) injection, and the balance abilities of each method are compared in [18]. A proposed modulation replaces the P-type or N-type small switching states with other switching state to balance the NPP in [23], however, this method increase the switching events and output total 
harmonic distortion. SVPWM adjusts the application time of the redundant space vectors to balance the NPP, but the control effect of this method is not satisfactory [19]. However, the problem of the NPP offset or low frequency oscillation is inevitable in the three-level NPC inverter [20].

Virtual SVPWM (VSVPWM) is capable of controlling the NP voltage under full modulation indexes and full power factors. A modified virtual space vector modulation scheme with the reduced uses of the medium voltage vectors is proposed in [21]. However, this modulation strategy is more complex than SVPWM, increases the switching frequency, and deteriorates the output waveforms of the inverter.

Another key technology for the three-level inverter is to reduce the switching losses. With the development of power semiconductor technology, the switching frequency of the switching device can be very high, and then the harmonic content of the inverter output can be reduced, especially for higher order harmonics. Nevertheless, with the increase of switching frequency, switching losses will increase simultaneously. A generalized power loss algorithm for multilevel neutral-point clamped (NPC) PWM inverters is presented, which is applicable to any level number of multilevel inverters in [24]. In order to reduce the switching losses, some other works have been researched [13, 25-27]. Although the soft-switching technique can be adopted to reduce switching losses effectively, it not only results in a higher system cost and control complexity, but is also limited by the modulation period [25]. Some studies proposed a discontinuous PWM strategy to reduce switching losses [26], which does not consider the problem of the NPP offset. SVPWM is adopted in [28], and the redundant vectors are used to reduce switching losses, which is to avoid switching the largest phase current by selecting the small vectors properly. But the experimental result is not obvious because of the limitation of the redundancy vectors. None of the aforementioned research discusses the modulation strategy under the NPP offset. Some studies introduce many multiple circuits replacing $\mathrm{Si}$ diode with $\mathrm{SiC}$ diode to reduce the switching loss [29]. Even the switching loss can be considerably reduced by the proposed method; the cost of the system is increased.

In this paper the CBPWM, SVPWM and RSLPWM for three-level NPC are first introduced. An ASPDPWM is proposed to modulate a three-level inverter under the NPP offset, which can output PWM sequences correctly and suppress the lower order harmonics of the inverter effectively. The mathematical model of the NPP with injected CMV is analyzed, and the calculation method of CMV for CBPWM is derived. Then, an NPP balance algorithm based on CBPWM is proposed. A hybrid modulation strategy combining RSLPWM and CBPWM with the NPP balance is proposed. Hysteresis strategy is adopted to switch between RSLPWM and the NPP balance based on CBPWM, so that both reduced switch losses and an acceptable NPP can be achieved. An experimental

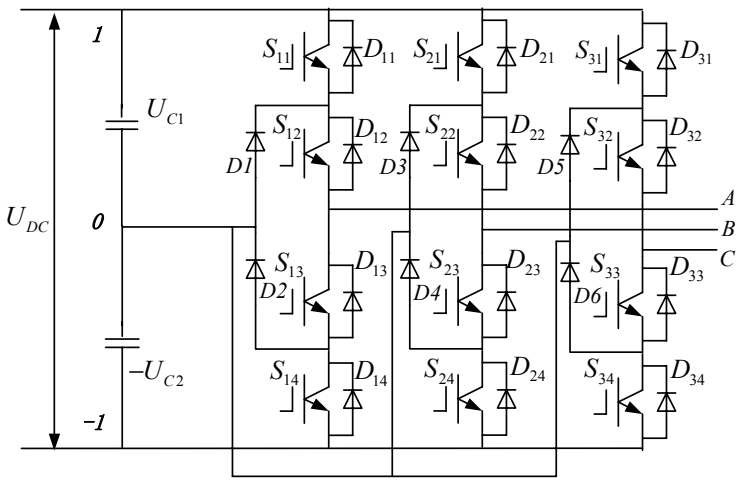

Fig. 1. The topology of the three-level NPC inverter

prototype of a three-level NPC inverter is built. The effectiveness of the hybrid modulation is verified with a resistance-inductance load and a PMSM load. The experimental results show that the hybrid modulation strategy can not only reduce switching losses but also control the NPP effectively.

Section 2 gives the structure and operating principle of the three-level inverter. Section 3 presents the modulation strategies of the three-level inverter. CBPWM with injected CMV is presented in Section 4. Section 5 presents the modulation strategy with the unbalanced NPP. Section 6 gives the principle of the NPP balance based on CBPWM. Hybrid strategy with the reduced switching losses and the NPP balance based on CBPWM is presented in Section 7. Experimental verification of the proposed strategy is given in Section 8.

\section{Structure and Operation of the Three-Level Inverter}

The topology of the three-level NPC inverter is shown in Fig. 1. Each phase consists of four switching devices with an anti-parallel freewheeling diode and two clamping diodes.

The NP is selected as a reference point. When $S_{11}$ and $S_{12}$ are ON, the output voltage is $U_{C l}$, denoted by 1 level. When $S_{12}$ and $S_{13}$ are ON, the output voltage is zero, denoted by 0 level. When $S_{13}$ and $S_{14}$ are ON, the output voltage is $-U_{C 2}$, denoted by -1 level.

\section{Modulation Strategies for the Three-level Inverter}

\subsection{CBPWM}

CBPWM for the multilevel inverter is derived from the PDPWM strategy proposed by Carrara [30]. The PWM wave is generated by comparing the multi-carriers with multi-modulation waves. Fig. 2 shows the principle of 


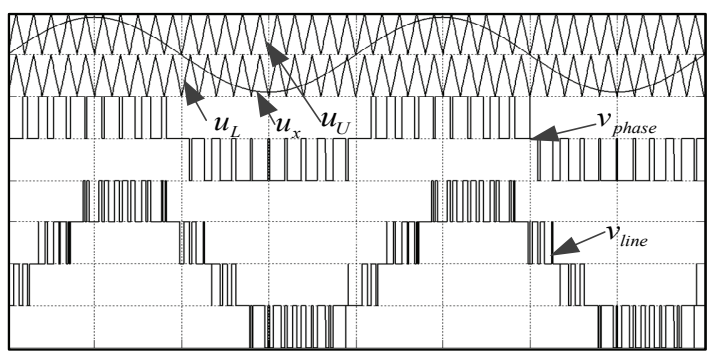

Fig. 2. PDPWM for the three-level inverter produced by comparing dual carriers with single-modulation wave

\section{PDPWM.}

If the dual carriers are arranged in the same phase but different position, the PDPWM strategy is achieved, which is one of CBPWM, where $u_{x}(x=A, B, C)$ is the instantaneous value of the modulation wave. When the NPP is balanced, the duty cycle of the three-phase output level can be expressed as:

$$
\left\{\begin{array}{l}
d_{x 1}=\frac{u_{x}}{U_{D C} / 2}, d_{x 0}=1-\frac{u_{x}}{U_{D C} / 2}, d_{x-1}=0,\left(u_{x} \geq 0\right) \\
d_{x 1}=0, d_{x 0}=1-\frac{-u_{x}}{U_{D C} / 2}, d_{x-1}=\frac{u_{x}}{U_{D C} / 2},\left(u_{x}<0\right)
\end{array}\right.
$$

where $d_{x-1}, d_{x 0}$, and $d_{x 1}$ are the duty cycle of the $-1,0$ and 1 level, respectively. The modulation waves will be changed by the injected $\mathrm{CMV}$, so that a variety of modulation strategies will be produced. These strategies are based on the synthesis principle of seven-segment modulation or the simplified five-segment modulation.

\subsection{SVPWM}

SVPWM strategy is based on the principle of vector synthesis. In one sample cycle, the reference vector is synthesized by the combination of the basic voltage vectors according to the volt-second equation principle.

The voltages of each level are substituted into (2), and the basic voltage vector, output from the inverter, can be obtained. Then the space vector for the three-level inverter is given in Fig. 3 (a). As the output voltage of each phase has three levels, $3^{3}$ space voltage vectors can be obtained in the three-level inverter.

$$
\mathbf{u}=\sqrt{\frac{2}{3}}\left(u_{A} \mathbf{e}^{j 0}+u_{B} \mathbf{e}^{j \frac{2 \pi}{3}}+u_{C} \mathbf{e}^{j \frac{4 \pi}{3}}\right)
$$

According to the vector length, the vectors of the threelevel inverter can be divided into zero voltage vectors (ZVVs), large voltage vectors (LVVs), medium voltage vectors (MVVs), upper small voltage vectors (USVVs) and lower small voltage vectors (LSVVs). The classification is shown in Table 1. When the NPP is balanced, the effects
Table 1. Space vector of three-level inverter

\begin{tabular}{c|l}
\hline \hline & \multicolumn{1}{|c}{ Vector Symbol } \\
\hline ZVV & $u_{00}[0,0,0], u_{0 \mathrm{~L}}[-1,-1,-1], u_{0 \mathrm{U}}[1,1,1]$ \\
\hline LSVV & $\begin{array}{l}\left.u_{1 \mathrm{~L}}[0,-1,-1], u_{2 \mathrm{~L}}[0,0,-1], u_{3 \mathrm{~L}}[-1,0,-1], u_{4 \mathrm{~L}}-1,0,0\right], u_{5 \mathrm{~L}}[-1,-1,0], \\
u_{6 L}[0,-1,0]\end{array}$ \\
\hline USVV & $u_{1 \mathrm{U}}[1,0,0], u_{2 \mathrm{U}}[1,1,0], u_{3 \mathrm{U}}[0,1,0], u_{4 \mathrm{U}}[0,1,1], u_{5 \mathrm{U}}[0,0,1], u_{6 \mathrm{U}}[1,0,1]$ \\
\hline MVV & $u_{7}[1,0,-1], u_{8}[0,1,-1], u_{9}[-1,1,0], u_{10}[-1,0,1], u_{11}[0,-1,1], u_{12}[1,-1,0]$ \\
\hline LVV & $\begin{array}{l}u_{13}[1,-1,-1], u_{14}[1,1,-1], u_{15}[-1,1,-1], u_{16}[-1,1,1], u_{17}[-1,-1,1], \\
u_{18}[1,-1,1]\end{array}$ \\
\hline
\end{tabular}

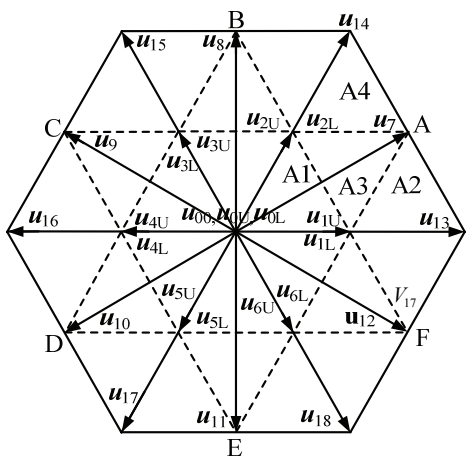

(a) Space vector of three-level inverter

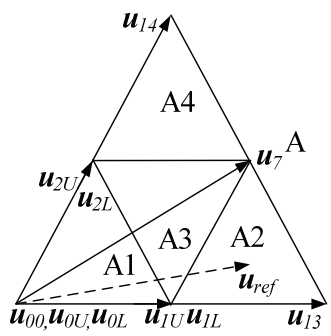

(b) Space vector of sector $\mathrm{A}$

Fig. 3. Space vector diagram of three-level inverter

on the load of USVV and LSVV are equal.

For example, when the reference vector $\boldsymbol{u}_{\text {ref }}$ is located in the small triangle A2, as shown in Fig. 3 (b), according to the Nearest Three Vector principle of SVPWM (NTVSVPWM), the following conditions need to be met:

$$
\left\{\begin{array}{l}
\boldsymbol{u}_{13} t_{13}+\boldsymbol{u}_{7} t_{7}+\boldsymbol{u}_{1 L} t_{1 L}+\boldsymbol{u}_{1 U} t_{1 U}=\boldsymbol{u}_{r e f} \\
t_{13}+t_{7}+t_{1 L}+t_{1 U}=1
\end{array}\right.
$$

When the upper and lower capacitor voltages are equal, the effect of voltage vector $\boldsymbol{u}_{1 L}$ is consistent with voltage vector $\boldsymbol{u}_{1 U}$, but the effects of $\boldsymbol{u}_{1 L}$ and $\boldsymbol{u}_{1 U}$ on the NPP are reversed. While keeping the $t_{1 U}+t_{1 L}$ unchanged, the NPP can be controlled by rearranging their application time. But when the upper and lower capacitor voltages are different, these conditions are untenable.

\section{CBPWM with the Injection of CMV}

In the control system of the three-phase inverter, the 
transformations and inverse transformations of Park and Clarke are usually adopted. The inverse Clarke transformation transforms the voltage to the three-phase stationary frame, and the transformation is expressed as:

$$
\left[\begin{array}{l}
u_{A} \\
u_{B} \\
u_{C}
\end{array}\right]=\sqrt{2 / 3}\left[\begin{array}{cc}
1 & 0 \\
-1 / 2 & \sqrt{3} / 2 \\
-1 / 2 & -\sqrt{3} / 2
\end{array}\right]\left[\begin{array}{l}
u_{\alpha} \\
u_{\beta}
\end{array}\right]
$$

Without the injection of CMV, the modulation wave $u_{x}$ of phase-x can be calculated from (4) directly, and then it is compared with the carriers to generate PWM signals. Different forms of CMV can be injected to achieve some specific PWM strategies and then the modulation wave $u_{x}^{\prime}$ can be expressed as:

$$
u_{x}^{\prime}=u_{x}+u_{C M V}
$$

\subsection{Equivalence between SVPWM and CBPWM}

By adjusting the allocation time of the SVV, a variety of SVPWM strategies can be produced. The Centered SVPWM (CSVPWM) strategy which assigns the application time of the SVV equally has an optimum harmonic characteristic. The equivalence between SVPWM and CBPWM can be obtained by injecting CMV $u_{C M V, C S V}$. The injection of CMV is given as follows [4]:

$$
\begin{gathered}
u_{x}^{\prime \prime}=u_{x}-\frac{\max \left(u_{x}\right)+\min \left(u_{x}\right)}{2}(x=A, B, C) \\
u_{x}^{\prime \prime \prime}=\left[u_{x}^{\prime \prime}+u_{D C}\right] \operatorname{modulo}\left(u_{D C}\right) \\
u_{C M V, \mathrm{CSV}}=-\frac{u_{D C}-\max \left(u_{x}\right)-\min \left(u_{x}\right)-\max \left(u_{x}^{\prime \prime \prime}\right)-\min \left(u_{x}^{\prime \prime \prime}\right)}{2}
\end{gathered}
$$

where N-1 is the number of equal-amplitude carriers, and modulo is the remainder function.

\subsection{RSLPWM}

When the three-phase inverter is in operation, if the switching devices of one phase have no switching actions, switching losses can be reduced effectively. In order to ensure the modulation is in linear range, the following conditions need to be met.

For example, when $u_{A}>0, u_{B}<0, u_{C}<0$, CMV $\left(u_{C M V, R S L}\right)$ is injected into the three-phase modulation voltages. The modulation voltage of phase- $\mathrm{A}$ is raised to the upper capacitor voltage $u_{C 1}$, the devices of phase-A have no switching action, and 1 level outputs in this control cycle. The injected CMV can be expressed as:

$$
u_{C M V, R S L}=u_{C 1}-u_{A}
$$

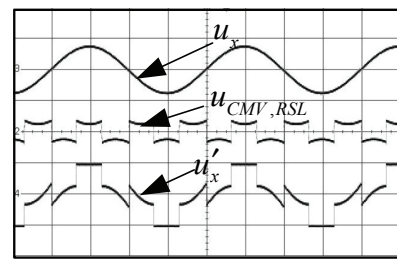

(a) CMV and modulated wave of RSLPWM

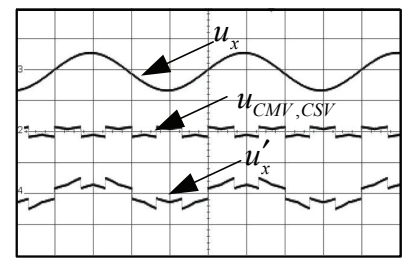

(b) CMV and modulated wave of SVPWM
Fig. 4. CMVs and modulation waves of RSLPWM and SVPWM based on CBPWM

When $u_{A}<0, u_{B}>0, u_{C}>0, \mathrm{CMV}$ is injected into the threephase modulation voltages. The modulation voltage of phase-A is reduced to the lower capacitor voltage $-u_{C 2}$, the devices of phase-A have no switching action, and -1 level outputs in this control cycle. The injected CMV can be expressed as:

$$
u_{C M V, R S L}=-u_{C 2}-u_{A}
$$

Fig. 4 shows the CMVs and modulation waves of RSLPWM and SVPWM based on CBPWM. Actually, in order to balance the NPP, other forms of CMVs need to be injected, and the relations of the injection of CMV analyzed in (8) - (10) cannot be used.

\section{Modulation Strategy under the Unbalanced NPP}

If the NPP of the three-level inverter is unbalanced, there will be two situations as follows: (1) The NPP fluctuates; (2) the NPP offsets. The former can be treated with a special modulation strategy, such as VSVPWM; the latter should be avoided as far as possible, or controlled within an acceptable range. Even though the NPP is mild unbalanced, the output of the inverter is also required to meet the requirements of harmonics, especially for lower order harmonics.

With the NPP offset, the heights of the upper and lower carriers are no longer equal, so ASPDPWM strategy is adopted, as shown in Fig. 5.

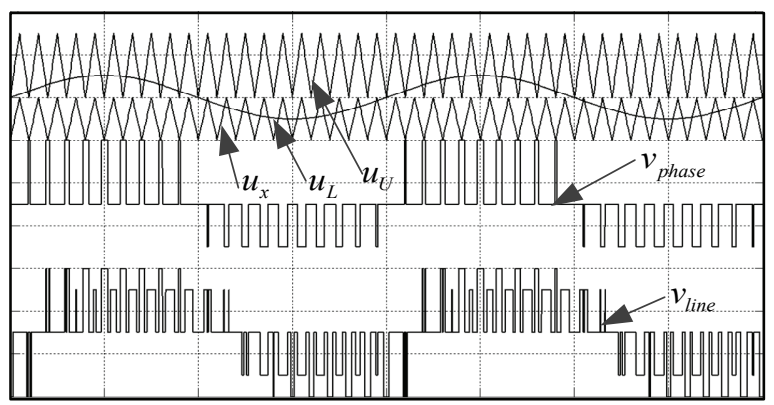

Fig. 5. Modulation principle of ASPDPWM 
In Fig. 5, $u_{U}$ is the upper carrier and $u_{C 1}$ is the height; and $u_{L}$ is the lower carrier and $u_{C 2}$ is the height. When $u_{x}>u_{U}, 1$ level outputs; when $u_{x}<u_{U}$ and $u_{x}>u_{L}, 0$ level outputs; when $u_{x}<u_{L},-1$ level outputs.

When $u_{x}>0,1$ and 0 level output, and their corresponding duty cycles are given as:

$$
d_{x 1}=\frac{u_{x}}{u_{C 1}}, d_{x 0}=1-d_{x 1}, d_{x-1}=0
$$

When $u_{x}<0, \quad 0$ and -1 level output, and their corresponding duty cycles are given as:

$$
d_{x 1}=0, d_{x 0}=1-d_{x-1}, d_{x-1}=\frac{-u_{x}}{u_{C 2}}
$$

When ASPDPWM strategy is adopted, even if the NPP offset occurs, the inverter can still output the correct PWM sequences without increasing the harmonics of the output voltage.

\section{The Principle of the NPP Balance}

\subsection{The NPP balance based on CBPWM}

Positive or negative current will be extracted from the NP by one phase that outputs 0 level (generally, the positive direction is defined as the outflow direction of the current), which will result in NPP offset. Within one carrier cycle, the magnitude and direction of the three-phase output currents can be considered as constant. According to (1), within one carrier cycle, the application time of 0 level can be expressed as:

$$
d_{x 0}=1-\frac{\left|u_{x}\right|}{u_{D C} / 2}
$$

In order to achieve the modulation, the average current extracted from the NP within one carrier cycle can be expressed as:

$$
i_{0}=\left(1-\frac{\left|u_{A}\right|}{u_{D C} / 2}\right) i_{A}+\left(1-\frac{\left|u_{B}\right|}{u_{D C} / 2}\right) i_{B}+\left(1-\frac{\left|u_{C}\right|}{u_{D C} / 2}\right) i_{C}
$$

In a three-phase three-wire system, if CMV is not injected, the following conditions should be satisfied: $u_{A}+u_{B}+u_{C}=0$ and $i_{A}+i_{B}+i_{C}=0$.

CMV $\left(u_{C M V, N P}\right)$ is injected into the three-phase voltages without changing their polarities. The average current $i_{0}{ }^{\prime}$ extracted from the NP within one carrier cycle can be expressed as:

$$
i_{0}^{\prime}=\left(1-\frac{\left|u_{A}+u_{C M V, N P}\right|}{u_{D C} / 2}\right) i_{A}+\left(1-\frac{\left|u_{B}+u_{C M V, N P}\right|}{u_{D C} / 2}\right) i_{B}+\left(1-\frac{\left|u_{C}+u_{C M V, N P}\right|}{u_{D C} / 2}\right) i_{C}
$$

When $u_{A}>0, u_{B}<0, u_{C}<0,-u_{A}<u_{C M V, N P}<\min \left\{\left|u_{B}\right|,\left|u_{C}\right|\right\}$, (14) and (15) can be simplified to (16) and (17) respectively:

$$
\begin{gathered}
i_{0}=\frac{2}{u_{D C}}\left(-u_{A} i_{A}+u_{B} i_{B}+u_{C} i_{C}\right) \\
i_{0}^{\prime}=i_{0}-\frac{4 u_{C M V, N P} i_{A}}{u_{D C}}=i_{0}+i_{0}^{\prime \prime}
\end{gathered}
$$

When $u_{A}>0, u_{B}>0, u_{C}<0, \min \left\{-u_{A},-u_{B}\right\}<u_{C M V, N P}<-u_{C}$, (14) and (15) can be simplified to (18) and (19) respectively:

$$
\begin{gathered}
i_{0}=\frac{2}{u_{D C}}\left(-u_{A} i_{A}-u_{B} i_{B}+u_{C} i_{C}\right) \\
i_{0}^{\prime}=i_{0}+\frac{4 u_{C M V, N P} i_{C}}{u_{D C}}=i_{0}+i_{0}^{\prime \prime}
\end{gathered}
$$

From (16) to (19), $i_{0}$ is the current used to achieve the modulation, extracted from the NP. $i_{0}^{\prime \prime}$ is the current increment, extracted from the NP after the CMV is injected and it is controlled by selecting proper $u_{C M V, N P}$ to achieve the control of the NPP.

$u_{y}(y=A, B, C)$ is assumed to be the phase voltage with the opposite sign to the other two phase voltages, and (17) and (19) can be written as a united expression:

$$
i_{0}^{\prime}=i_{0}-\operatorname{sgn}\left(u_{y}\right) \frac{4 u_{C M V, N P} i_{y}}{u_{D C}}=i_{0}+i_{0}^{\prime \prime}
$$

where $\operatorname{sgn}()$ is the sign function.

\subsection{Calculating CMV according to the load current, DC-link voltage and capacitance}

The equivalent model of the NPP is the upper and lower capacitors in parallel. The capacitance and the voltage value of the upper and lower capacitors are $C 1, u_{C 1}$ and $C 2, u_{C 2}$, respectively. The voltage deviation value of the upper and lower capacitor voltages is $\Delta u_{C}=u_{C 2}-u_{C 1}$. In order to eliminate the voltage deviation value, within one carrier cycle, the average current that needs to be extracted from the NP is given as:

$$
\overline{i_{0}}=\frac{(C 1+C 2) \Delta u_{C}}{T_{s}}
$$

To balance the NPP, $u_{C M V, N P 1}$ must be injected:

$$
u_{C M V, N P 1}=-\operatorname{sgn}\left(u_{y}\right) \frac{(C 1+C 2) \Delta u_{C} u_{D C}}{4 i_{y} T_{s}}
$$

In order to balance the NPP offset caused by $i_{0}$, 


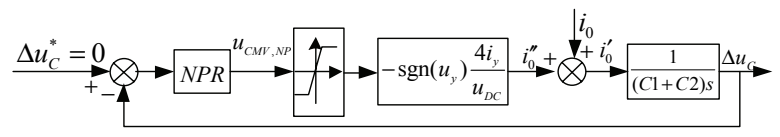

(a) Control block diagram of the NPP regarding $i_{0}$ as a disturbing term

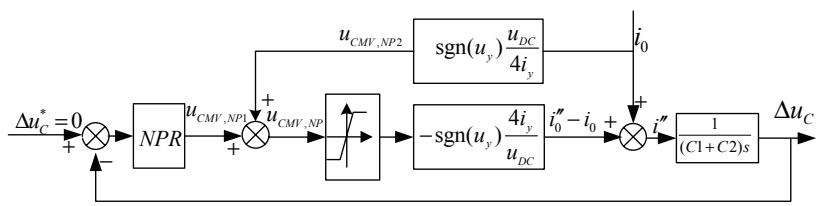

(b) Control block diagram of the NPP regarding $i_{0}$ as a feed forward term

Fig. 6. Control diagram for the NPP with and without consideration of $i_{0}$

$u_{C M V, N P 2}$ needs to be injected as:

$$
u_{C M V, N P 2}=\operatorname{sgn}\left(u_{y}\right) \frac{i_{0} u_{D C}}{4 i_{y}}
$$

The total CMV should be injected as:

$u_{C M V, N P}=u_{C M V, N P 1}+u_{C M V, N P 2}=\frac{\operatorname{sgn}\left(u_{y}\right) u_{D C}}{4 i_{y}}\left(i_{0}-\frac{C 1+C 2}{T_{s}} \Delta u_{C}\right)$

In Fig. 6(a), the difference between $\Delta u_{C}^{*}$ and the voltage-deviation feedback value $\Delta u_{C}$ inputs into the NPP regulator (NPR), and $u_{C M V, N P}$ output from the NPR is transformed into the current $i_{0}^{\prime \prime}$ which is used to balance the NPP by a multi-branch switch model. The total current $i_{0}^{\prime}$ injected into the NP is the sum of the current $i_{0}^{\prime \prime}$ and the disturbance term current $i_{0}$. The actual voltage deviation of the upper and lower capacitor voltages is obtained by $i_{0}^{\prime}$ after getting through the integral link of the capacitor. CMV is injected into the three-phase voltages to change the average current extracted from the NP. Then, $\Delta u_{C}$ is changed by the average current to control the NPP.

In Fig. 6(b), the current $i_{0}$ is treated as the feed forward term, and by using (23), $\mathrm{CMV}\left(u_{C M V, N P 2}\right)$ is acquired.

\subsection{Amplitude limiting of CMV}

After the injection of CMV, to guarantee the achievement of modulation, the amplitude of the injected CMV needs to be limited. There are two principles: (1) the polarities of the voltages should not be changed; (2) overmodulation should be avoided.

When $u_{A}>0, u_{B}<0, u_{C}<0$, the CMV should be limited as:

$$
\left\{\begin{array}{l}
-u_{A}<u_{C M V, N P}<\min \left\{-u_{B},-u_{C}\right\} \\
u_{C 1}-u_{A} \geq u_{C M V, N P} \geq-u_{C 2}-\min \left\{u_{B}, u_{C}\right\}
\end{array}\right.
$$

When $u_{A}<0, u_{B}>0, u_{C}>0$, the CMV should be limited as:

$$
\left\{\begin{array}{l}
-u_{A}>u_{C M V, N P}>\min \left\{-u_{B},-u_{C}\right\} \\
u_{C 1}-\max \left\{u_{B}, u_{C}\right\} \geq u_{C M V, N P} \geq-u_{C 2}-u_{A}
\end{array}\right.
$$

In (25) and (26), the first one is the constraints of condition (1), and the second one is the constraints of condition (2).

\section{Hybrid Strategy with the Reduced Switching Losses and the NPP Balance Based on CBPWM}

In order to achieve the modulation strategy of the threelevel inverter, the following requirements must be satisfied. (1) Reduce the harmonics as much as possible, especially for lower order harmonics; (2) ensure the NPP balance, or control NPP offset within an acceptable range; (3) reduce switching losses and achieve high efficiency. According to the voltage value of the upper and lower capacitors, the degree of the NPP offset can be defined as follows:

$$
e=\frac{\Delta u_{C}}{u_{C 1}+u_{C 2}} \times 100 \%
$$

According to the analysis in Section 4.2 and Section 5, injecting CMV can not only reduce switching losses of switching devices to achieve RSLPWM, but also control the NPP offset. However, of the two conditions, only one can be selected and satisfied at a time.

In this paper, the proposed hybrid modulation strategy not only ensures NPP balance, but also reduces switching losses. So the existence of the NPP offset must be allowed. But it should be controlled within an acceptable range.

To achieve the hybrid modulation strategy, hysteresis control is adopted to switch between RSLPWM and CBPWM with NPP balance, as shown in Fig. 7. The hysteresis control has some advantages like real-time control, rapid response speed, and good robustness. The loop width is determined by the predefined NPP offset. The real-time NPP offset can be gained by measured the upper and lower capacitor voltages. When the NPP offset is over the predefined upper limit, CBPWM with the NPP balance becomes effective until the NPP offset is lower

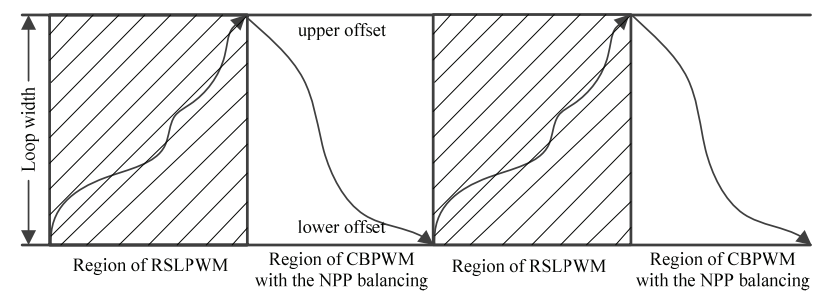

Fig. 7. The hysteresis control logic of hybrid modulation strategy 


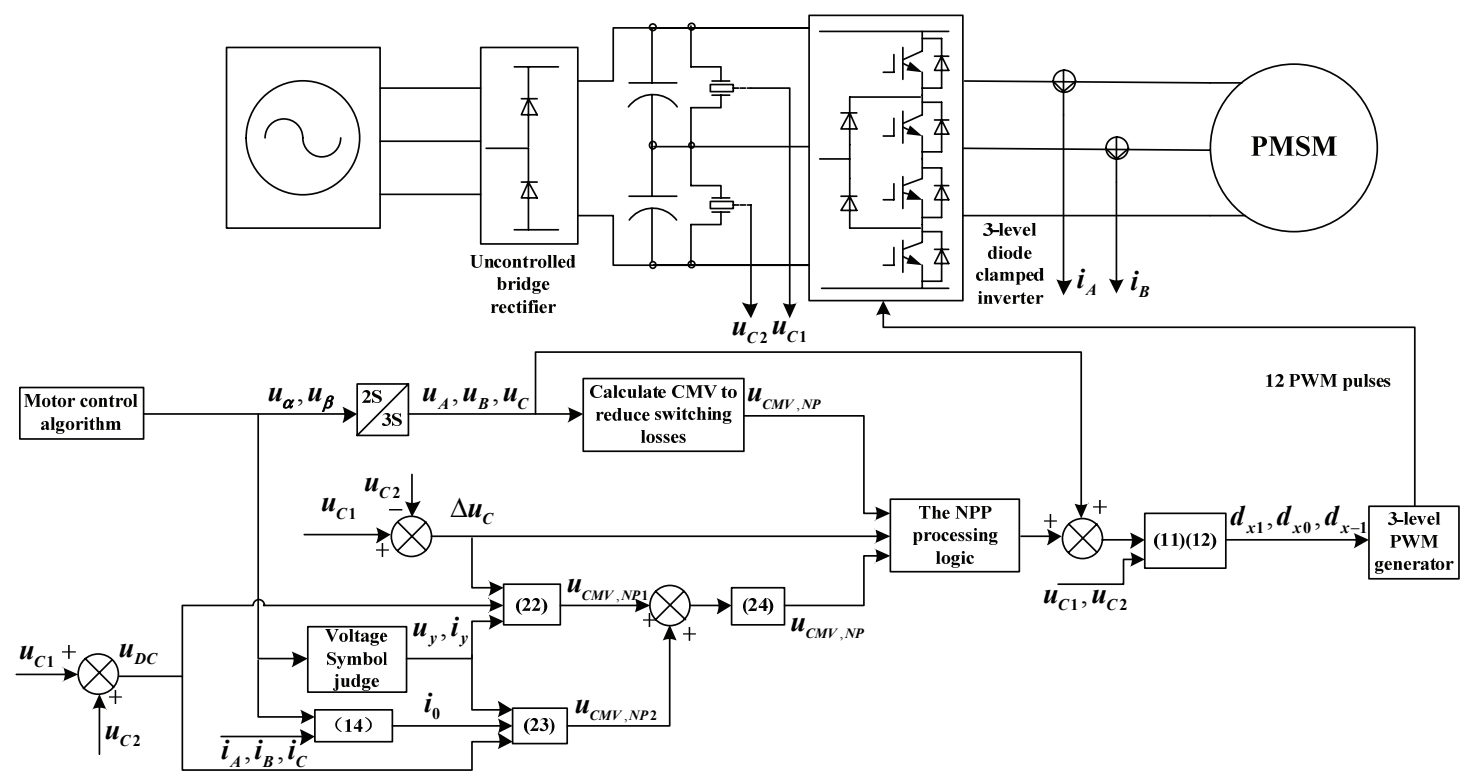

(a) The system block diagram of the entire control system

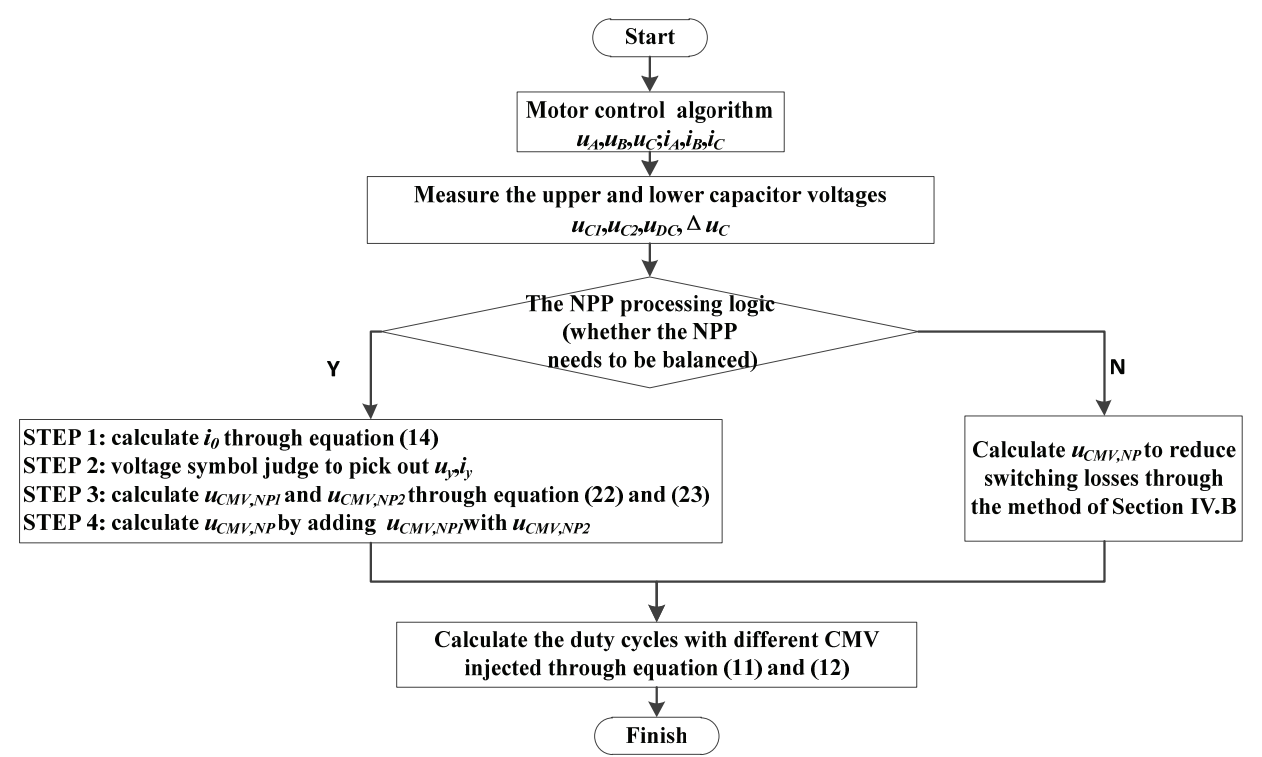

(b) The flow chart of the entire control system

Fig. 8. The system block diagram and the flow chart of the entire control system

than the predefined lower limit, and the process is named as Region of CBPWM with the NPP balancing. Otherwise, then RSLPWM with the reduced switching losses becomes effective until the NPP offset is over the predefined upper limit and the process is named as Region of RSLPWM. The system switches between the two regions to generate the correct PWM sequences and suppress the lower order harmonics. At the same time, the switching loss is reduced effectively.

Fig. 8(a) shows the control diagram of the entire system, and the required outputs $u_{\alpha}$ and $u_{\beta}$ of the inverter are calculated by the other control algorithm. After $2 \mathrm{~S} / 3 \mathrm{~S}$ transformations, outputs $u_{A}, u_{B}$ and $u_{C}$ of the inverter are calculated. The NPP processing logic determines whether the NPP needs to be balanced according to the difference between the upper and lower capacitor voltages. If necessary, CMV is injected according to NPP balancing algorithm which is introduced in Section 5. The NPP balancing algorithm can be divided into following steps. First, substituting the inverter output voltages $u_{A}, u_{B}, u_{C}$ and output currents $i_{A}, i_{B}, i_{C}$ into (14), the current used to achieve the modulation $i_{0}$ can be calculated. Second, the voltage symbol judge is used to pick out the phase voltage and current $\left(u_{y}, i_{y}\right)$ which is different from others. Third, substituting the capacitance and voltage deviation value of the upper and lower capacitors ( $C 1$, $C 2, \Delta u_{c}$ ), DC-link voltage $u_{D C}$ and $u_{y}, i_{y}$ into (22), the injected CMV $u_{C M V, N P 1}$ can be calculated. Substituting 
$i_{0}, u_{y}, i_{y}, u_{D C}$ into (23), the injected CMV $u_{C M V, N P 2}$ can be calculated. Last, the total CMV can be obtained by adding $u_{C M V, N P 1}$ with $u_{C M V, N P 2}$. Otherwise, CMV is injected according to the method of Section 4.2. As the inverter needs to run at the condition of the NPP offset, the ASPDPWM strategy given in Section 5 is adopted to ensure that the output of the PWM sequences is correct and the duty cycle is written into the compare value register of DSP. Finally, the output pulses are generated by comparing $u_{A}, u_{B}$ and $u_{C}$ with the triangular carrier. The flow chart of the entire control system is shown as Fig. 8(b).

\section{Experimental Verification}

In order to verify the effectiveness of the control strategy proposed in this paper, an NPC three-level inverter experimental prototype was built, as shown in Fig. 9. DSP MC56F8345 manufactured by Freescale is used as the main control chip, the switching device is IGBT G60N100BNTD, and the clamp diode is RHRG50120F. DC-link voltage is obtained by using a diode rectifier or batteries. Table 2 shows the system parameters.

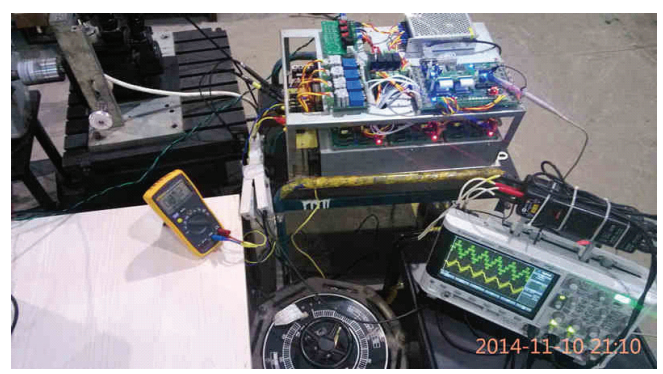

(a) Three-level experimental prototype

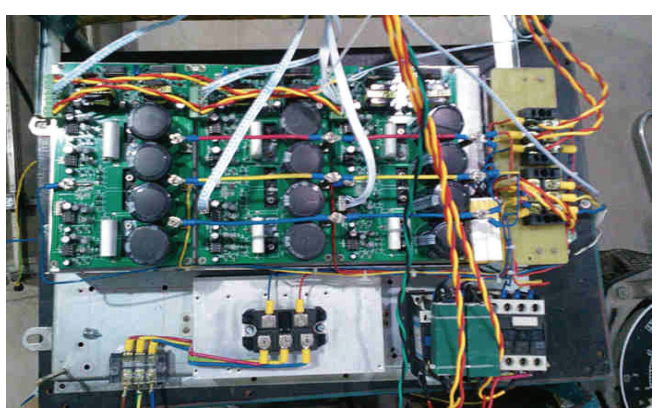

(b) Section layout of switching devices

Fig. 9. Experimental prototype of the NPC three-level inverter

Table 2. System parameters

\begin{tabular}{c|c}
\hline$U_{D C}$ & $250 \mathrm{~V}$ \\
\hline $\mathrm{C} 1$ & $705 \mathrm{uF}$ \\
\hline $\mathrm{C} 2$ & $705 \mathrm{uF}$ \\
\hline Switching frequency & $6 \mathrm{kHz}$ \\
\hline NPP offset high limiting & $\pm 4 \%$ \\
\hline NPP offset low limiting & $\pm 0.5 \%$ \\
\hline
\end{tabular}

\subsection{Comparison between SVPWM and RSLPWM}

CSVPWM and RSLPWM are compared under the NPP balance (using two independent power supplies to maintain the NPP balance), and the phase-voltage, line-voltage waveforms and corresponding higher order harmonics are shown in Fig. 10 and Fig. 11. In Fig. 11 (a), the switching devices have no switching action within about one third sinusoidal cycle under RSLPWM, which is consistent with the above theoretical analysis. Comparing Fig. 10(d) and Fig. 11(d), the harmonic of the line voltage around the switching frequency and the double switching frequency under RSLPWM is slightly greater than that under CSVPWM. Therefore, to reduce switching losses, meanwhile, certain harmonic characteristics must be sacrificed.

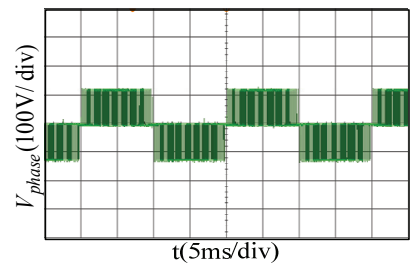

(a) Phase voltage

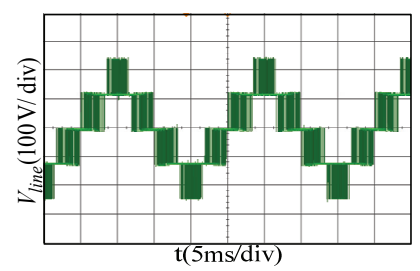

(c) Line voltage

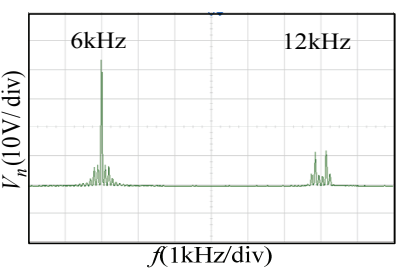

(b) Phase voltage spectrum

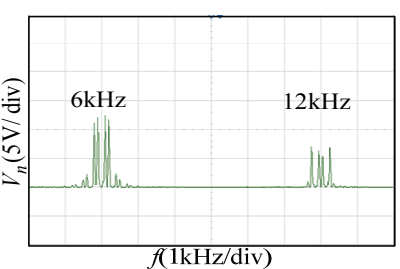

(d) Line voltage spectrum
Fig. 10. The waveforms and spectrums of voltages under CSVPWM

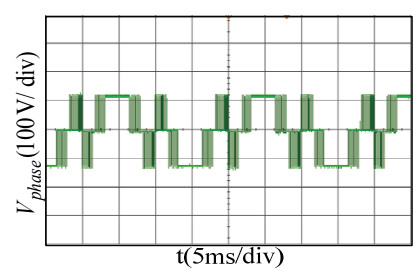

(a) Phase voltage

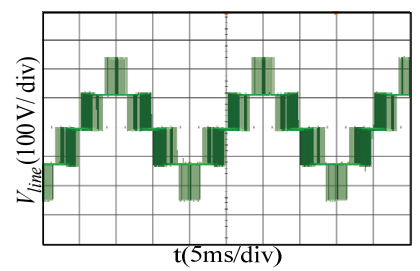

(c) Line voltage

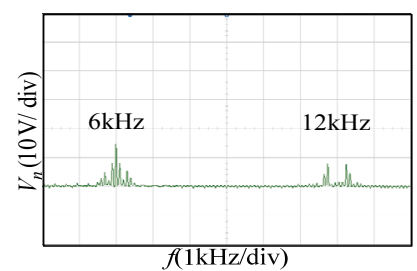

(b) Phase voltage spectrum

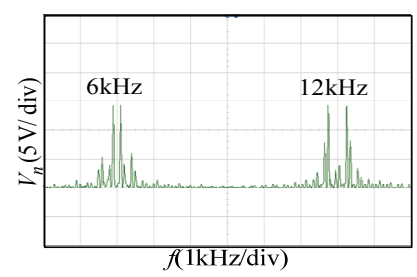

(d) Line voltage spectrum
Fig. 11. The waveforms and spectrums of voltages under RSLPWM 


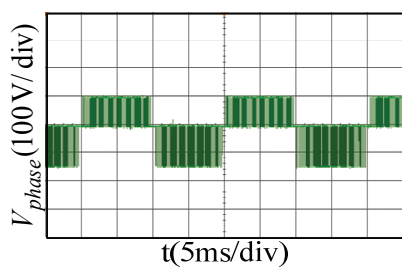

(a) Phase voltage of CSVPWM

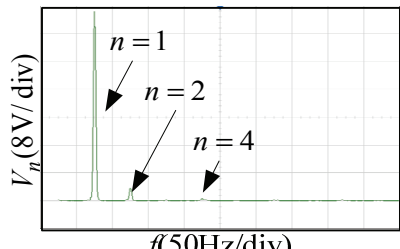

(c) Phase voltage spectrum of CSVPWM

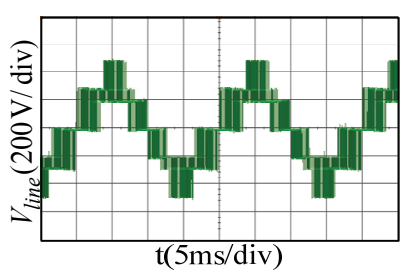

(e) Line voltage of CSVPWM

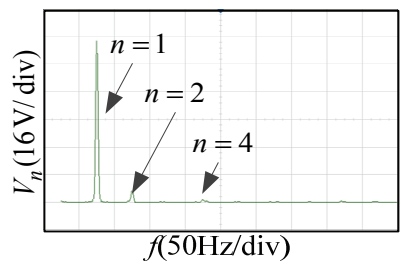

(g) Line voltage spectrum of CSVPWM

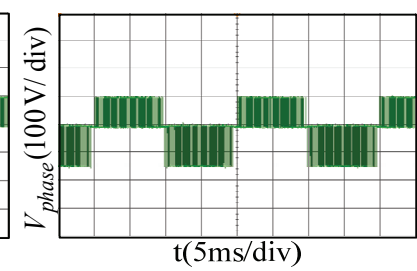

(b) Phase voltage of ASPDPWM

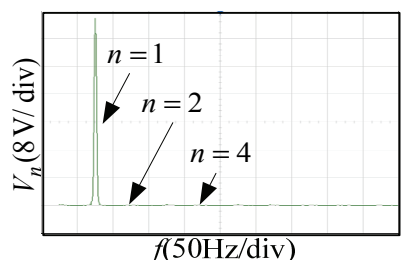

(d) Phase voltage spectrum of ASPDPWM

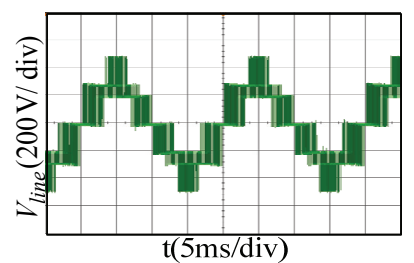

(f) Line voltage of ASPDPWM

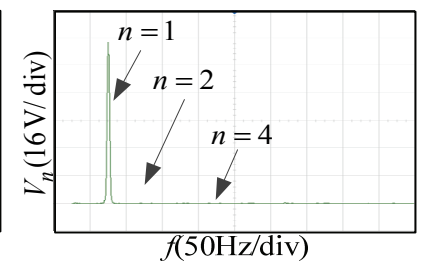

(h) Line voltage spectrum of ASPDPWM

Fig. 12. The results of CSVPWM and ASPDPWM with a serious NPP offset

\subsection{Comparison between CBPWM and ASPDPWM under the NPP offset}

Fig. 12 shows the line-voltage and phase voltage waveforms, and their corresponding lower order harmonics under ASPDPWM and CBPWM, respectively. When the NPP offset is serious ( $e=20 \%$ ), the line and phase voltages of ASPDPWM do not contain the lower order harmonics. But a certain amount of the even lower order harmonics appears in the line and phase voltages under CSVPWM. When the NPP offset is serious, ASPDPWM can substitute the upper and lower capacitor voltages into the calculation of the duty cycle effectively, thereby reducing the harmonic.

\subsection{Comparison of the NPP under different modulat- ion algorithms}

Fig. 13 shows the offset and fluctuation of the NPP under CSVPWM and RSLPWM without the NPP balance

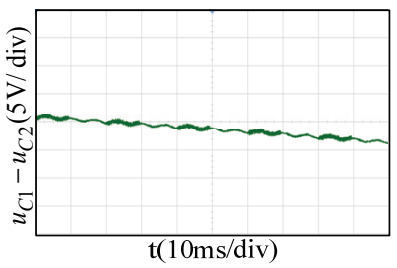

(a) CSVPWM $(\mathrm{m}=0.4)$

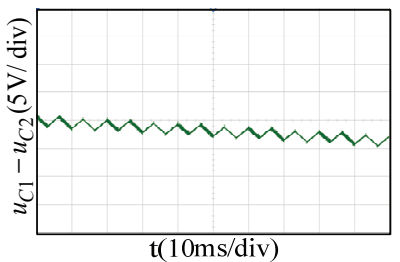

(c) RSLPWM (m=0.4)

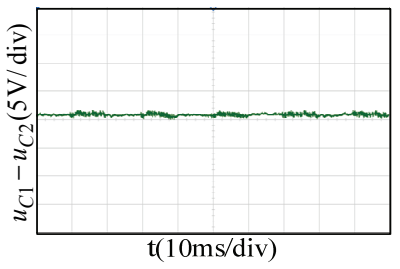

(e) CBPWM with the NPP balance $(\mathrm{m}=0.4)$

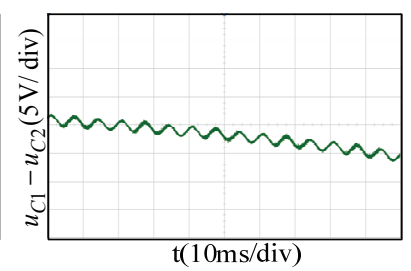

(b) CSVPWM $(\mathrm{m}=0.8)$

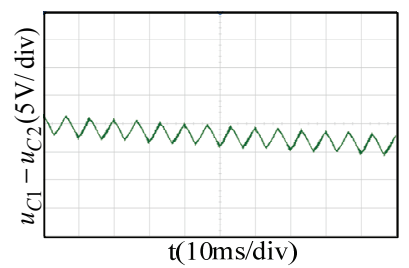

(d) RSLPWM ( $\mathrm{m}=0.8)$

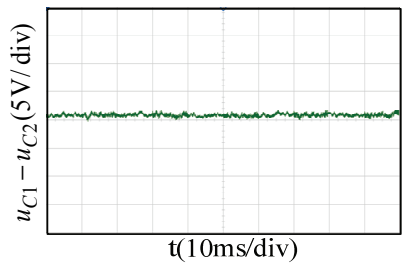

(f) CBPWM with the NPP balance $(\mathrm{m}=0.8)$

Fig. 13. Differences between the upper and lower capacitor voltages of CSVPWM, RSLPWM and CBPWM with the NPP balance under different modulation degrees

and CBPWM with the NPP balance at the condition of different modulation degrees $(\mathrm{m}=0.4$ and $\mathrm{m}=0.8)$. It can be seen that the NPP offset and fluctuation exist under CSVPWM and RSLPWM, and the form of fluctuation under CSVPWM is close to a sinusoidal wave with a frequency three times that of the fundamental, while the fluctuation of RSLPWM is close to a triangular wave with the frequency three times that of the fundamental. From Fig. 13 (a) to (d), the impact of the unbalanced NPP on the inverter is more serious than the fluctuation. With the difference of capacitor voltage, the NPP offset accelerates, and ultimately, the inverter will stop running because of the protection of the NPP.

From Fig. 13 (e) and (f), when CBPWM with the NPP balance is adopted, although the high-frequency fluctuation of the NPP exists around the switching frequency, the average value of fluctuation is small and the waveforms of the upper and lower capacitor voltages substantially coincide. Therefore, the CBPWM is able to deal with the NPP balance problem effectively.

\subsection{Verification of the Proposed Algorithm with a Resistance-Inductance Load}

The experimental results of the hybrid modulation strategy proposed in this paper are shown in Fig. 14 and 
Fig. 15, where the three-level inverter has a resistanceinductance load. The upper limit of the NPP offset is set to $4 \%$ of the DC-link voltage, and the lower limit is $0.5 \%$ of the DC-link voltage.

Fig. 14 and Fig. 15 show the waveforms of the phase voltage and the capacitor voltage of the inverter under different modulation degrees. When $\mathrm{m}=0.4$, the application time of RSLPWM is about $280 \mathrm{~ms}$ and that of CBPWM is about $31 \mathrm{~ms}$ in the hybrid modulation strategy. When $\mathrm{m}=$ 0.8 , the application time of RSLPWM is about $320 \mathrm{~ms}$ and that of CBPWM is about $12 \mathrm{~ms}$ in the hybrid modulation strategy. As the modulation degree is high, the output current from the inverter is larger, which can better balance the NPP. From the results, RSLPWM is the major strategy adopted in the entire hybrid modulation strategy rather than CBPWM with the NPP balance. Therefore, the hybrid modulation strategy can effectively improve the efficiency

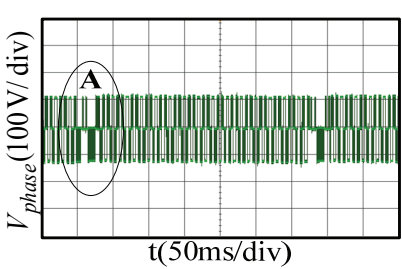

(a) Phase voltage

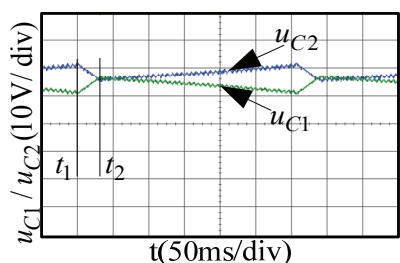

(c) Upper and lower capacitor voltage

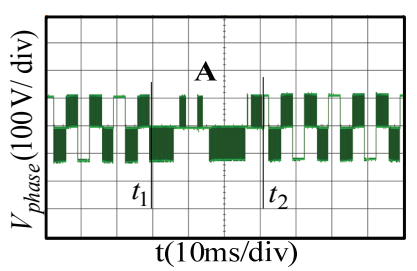

(b) Expansion of section $\mathrm{A}$

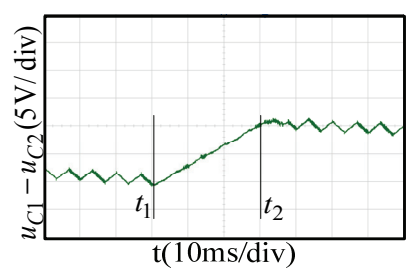

(d) Expansion of the NPP
Fig. 14. The waveforms of the hybrid strategy with a resistance-inductance load when $\mathrm{m}=0.4$

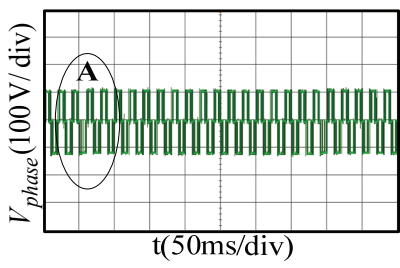

(a) Phase voltage

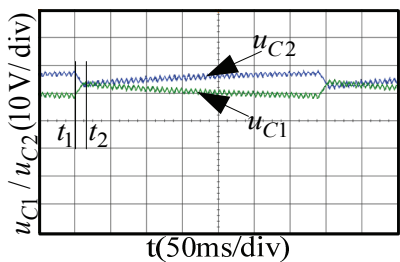

(c) Upper and lower capacitor voltage

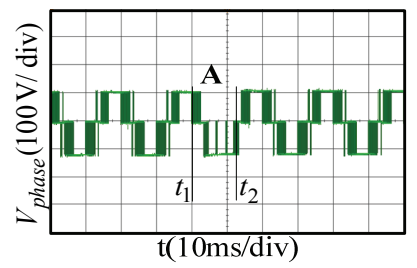

(b) Expansion of section $\mathrm{A}$

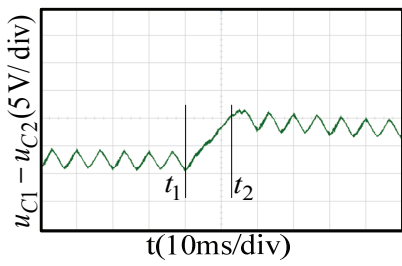

(d) Expansion of the NPP
Fig. 15. The waveforms of the hybrid strategy with a resistance-inductance load when $\mathrm{m}=0.8$ of the system by reducing switching losses and the device heating. The specific experimental process can be seen in the next subsection.

\subsection{Comparison of efficiency and heating of systems with a resistance-inductance load}

Fig. 16 and Fig. 17 show the comparison of conventional CBPWM with the hybrid modulation strategy proposed in this paper in terms of the efficiency and the heating of the system. The efficiency of the system can be increased by $0.5 \%$ to $1 \%$ by using the proposed strategy in this paper. Fig. 17 shows the infrared thermography of power switches in phase A. The power switches in other phase is as same as phase A. As the heating of $S_{2}$ and $S_{3}$ is the highest, the device temperature needs to be tested and recorded. The initial temperature was $18^{\circ} \mathrm{C}$, and the final temperature under the hybrid modulation strategy was $39.9^{\circ} \mathrm{C}$ for an hour's operation, while the final temperature using CBPWM was $41.9^{\circ} \mathrm{C}$. The temperature of $D_{1}, D_{2}, S_{1}$ and $S_{4}$

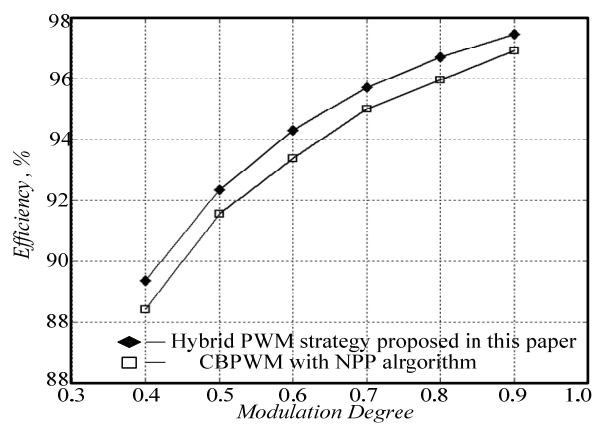

Fig. 16. Comparison of efficiency of CBPWM and the proposed strategy with a resistance-inductance load

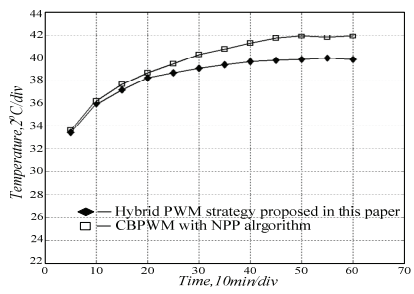

(a) Temperatures curve

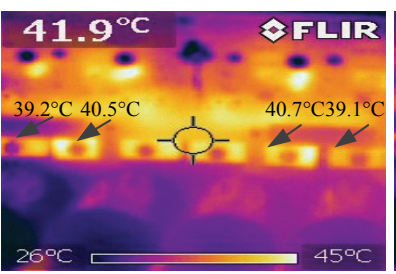

(c) Infrared thermography of CBPWM

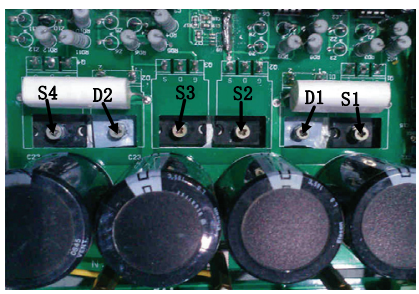

(b) Layout of single-phase switching devices

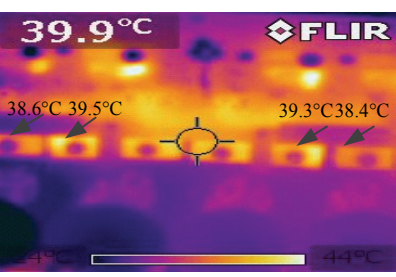

(d) Infrared thermography of the proposed algorithm
Fig. 17. The temperatures of devices under CBPWM and the proposed strategy 
is also marked in Fig. 17. It can be concluded that the proposed hybrid modulation strategy can improve the efficiency and reduce switching losses.

\subsection{Verification of the proposed hybrid algorithm with dynamic load}

To verify the dynamic response of the proposed modulation algorithm, the PMSM is chosen as the control object. When the PMSM is accelerated, the three-level NPC inverter should output the higher power instantaneously. The DC-link voltage decreases during this process and the expanded views are shown in Fig. 18 (b) and (c). It can be seen that, during this process, both the upper and lower capacitor voltages are reduced, while the difference between the upper and lower capacitor voltages is located within the predefined threshold. When the difference reaches the predefined value, the NPP balance algorithm becomes effective, and then the difference is decreased. When the upper and lower capacitor voltages are consistent, RSLPWM becomes effective, and then the NPP offset occurs. The process of the NPP offset is repeated, so the NPP can be controlled in an acceptable range, and switching losses are reduced.

For the deceleration of the motor, as shown in Fig. 18 (d), (e), similar results can be obtained, showing that the hybrid modulation strategy proposed in this paper is

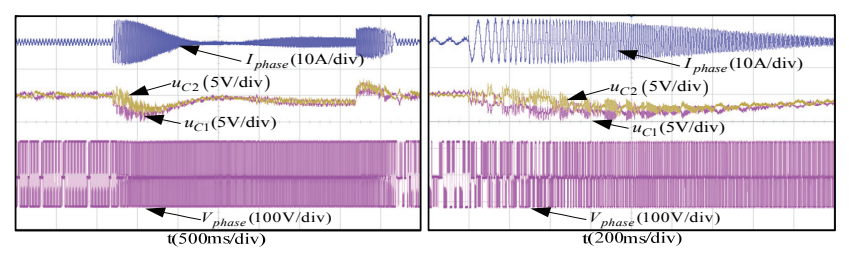

(a) Experimental results of acceleration deceleration for one cycle

(b) Expansion of and acceleration

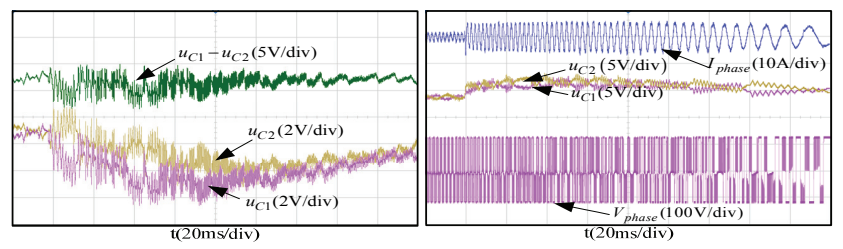

(c) Capacitor voltage difference in acceleration process

(d) Expansion of deceleration process

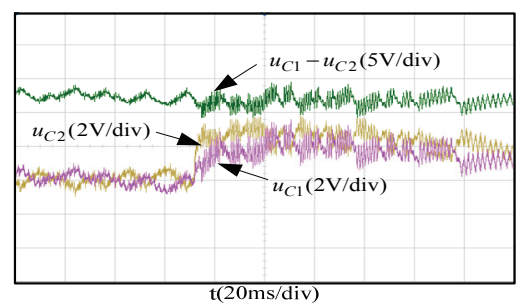

(e) Capacitor voltage difference in deceleration process

Fig. 18. Application of the proposed algorithm in the driving system for PMSM effective for this type of load, which has fast dynamic response requirements.

\section{Conclusion}

In this paper, a hybrid modulation strategy combining RSLPWM and CBPWM with the NPP balancing algorithm is proposed. The NPP can be controlled within acceptable values by using CBPWM with the NPP balance algorithm, and switching losses are reduced when RSLPWM is adopted. The proposed hybrid modulation strategy can be carried out by injecting different CMVs. Because CBPWM with the NPP balancing algorithm proposed is not used in every sample cycle, the fluctuation and offset on the NPP are bound to exist. Therefore, ASPDPWM, which is a modification of traditional CBPWM, is proposed in this paper. It can generate the correct PWM sequences and suppress the lower order harmonics effectively.

\section{References}

[1] H. Bai and Z. M. Zhao, "Framework and research methodology of short timescale plused power phenomena in high-voltage and high-power converters," IEEE Transactions on Industrial Electronics, vol. 56, no. 3, pp. 805-816,Mar. 2009.

[2] Z. Zhao, Y. Zhong, H. Gao, L. Yuan, and T. Lu, "Hybrid selective harmonic elimination PWM for common-mode voltage reduction in threelevel neutralpoint-clamped inverters for variable speed induction drives," IEEE Transactions on Power Electronics, vol. 27, no. 3, pp. 1152-1158, Mar. 2012.

[3] J. Mathew, P.P. Rajeevan, K. Mathew, N.A. Azeez and K. Gopakumar, "A multilevel inverter scheme with dodecagonal voltage space vectors based on flying capacitor topology for induction motor drives," IEEE Transactions on Power Electronics, vol. 28, no. 1, pp. 516-525, Feb. 2013.

[4] B. Singh and V.S. Kadagala, "Simulation of threelevel 24-pulse voltage source converters-based static synchronous compensator for reactive power control," IET Power Electronics, vol. 7, no. 5, pp. 1148-1161, May. 2014.

[5] O. Vodyakho and T. Kim, "Shunt active filter based on three-level inverter for three-phase four-wire systems," IET Power Electronics, vol. 2, no. 3, pp. 216-226, Mar. 2009.

[6] Y. Wang, W. W. Shi, N. Xie, and C. M. Wang, "Diode free T-type three level neutral-point-clamped inverter for low voltage renewable energy system," IEEE Transactions on Industrial Electronics, vol. 61, no. 11, pp. 6168-6174, Nov.2014.

[7] M. Schweizer and J. W. Kolar, "Design and implementation of a highly efficient three-level T- 
type converter for low-voltage applications," IEEE Transactions on Power Electronics, vol. 28, no. 2, pp. 899-907, Feb. 2013.

[8] W. Song, X. Feng, and K. M. Smedley, "A carrierbased PWM strategy with the offset voltage injection for single-phase three-level neutral-point clamped converters," IEEE Transactions on Industrial Informatics, vol. 28, no. 3, pp. 1083 -1095, Mar. 2013.

[9] J. Pou, J. Zaragoza, S. Ceballos, M. Saeedifard, and D. Boroyevich, "A carrier-based PWM strategy with zero-sequence voltage injection for a three-level neutral-point-clamped converter," IEEE Transactions on Power Electronics, vol. 29, no. 2, pp. 642-651, Feb.2012.

[10] W.D. Jiang,W.M. Li, Z.Q. Wu, Y.Y. She and Z.R. Tao, "Space-vector pulse-width modulation algorithm for multilevel voltage source inverters based on matrix transformation and including operation in the overmodulation region", IET Power Electronics, Vol. 7, no. 12 , pp. 2925-2933, Dec.2014.

[11] V. S. S. P. K. Hari and G. Narayanan, "Space-vectorbased hybrid pulse width modulation technique to reduce line current distortion in induction motor drives," IET Power Electronics, vol. 5, no. 8, pp. 1463-1471, Jul. 2012.

[12] B. Jacob, and M. R. Baiju, "A new space vector modulation scheme for multilevel inverters which directly vector quantize the reference space vector," IEEE Transactions on Industrial Electronics, vol. 62, no. 1, pp. 88-95, Jan. 2015.

[13] U.M. Choi, J. S. Lee and K. B. Lee, "Simple neutralpoint voltage control for three-level inverter using a discontinuous pulse width modulation," IEEE Transactions on Energy Conversion, vol. 28, no. 2, pp. 434-443, June 2013.

[14] J.-S. Lee and K.-B. Lee, "Carrier-based discontinuous PWM method for Vienna rectifiers," IEEE Transactions on Power Electronics, vol. 30, no. 6, pp. 28962900, Feb. 2015.

[15] B. P. McGrath, D. G. Holmes and T. Meynard. "Reduced PWM harmonic distortion for multilevel inverters operating over a wide modulation range," IEEE Transactions on Industrial Electronics, vol. 21, no. 4, pp. 941 -949, April. 2006.

[16] E. Sakasegawa and K. Shinohara, "Compensation for neutral point voltage in three-level inverter by using motor currents," IEEE Transactions on Industrial Electronics, vol. 121, no. 8, pp. 855-861, Aug. 2001.

[17] C. L. Xia, X. Gu, T. N. Shi, and Y. Yan, "Neutralpoint potential balancing of three-level inverters in direct-driven wind energy conversion system," IEEE Transactions on Energy Conversion, vol. 26, no. 1, pp. 18-29, Mar. 2011.

[18] W. D. Jiang, B. W Yang, J. Huang, Y. Y. She. "Comparisons of the Neutral Point Voltage Balancing Algorithm for NPC Three-level Inverters Based on
Different Zero-sequence Voltage Injection," Proceedings of the CSEE, vol. 33, no. 33, pp. 17-25, Nov. 2013, (in Chinese)

[19] H. A. Hotait, A. M. Massoud, S. J. Finney and B. W. Williams, "Capacitor voltage balancing using redundant states of space vector modulation for five-level diode clamped inverters," IET Power Electronics, vol. 3, no. 2, pp. 292-313, Feb. 2010.

[20] W.D. Jiang, S.W. Du, L.C. Chang, Y. Zhang, and Q. Zhao, "Hybrid PWM strategy of SVPWM and VSVPWM for NPC three-level voltage source inverter," IEEE Transactions on Power Electronics, vol. 25, no. 10, pp. 2607-2619, Oct. 2010.

[21] Abhijit Choudhury, Pragasen Pillay and Sheldon S. Williamson. "DC-Bus Voltage Balancing Algorithm for Three-Level Neutral-Point-Clamped (NPC) Traction Inverter Drive With Modified Virtual Space Vector," IEEE Transactions on Industry Applications, vol. 52, no. 5, pp. 3958-3967, Oct. 2016.

[22] G. I. Orfanoudakis, M. A. Yuratich, and S. M. Sharkh, "Nearest-vector modulation strategies with minimum amplitude of low-frequency neutral point voltage oscillations for the neutral-point-clamped converter," IEEE Transactions on Power Electronics, vol. 28, no. 10, pp. 4485-4499, Oct. 2013.

[23] U. M. Choi, J. S. Lee and K. B. Lee, "New modulation strategy to balance the neutral-point voltage for three-level neutral-clamped inverter systems," IEEE Transactions on Power Electronics, vol. 29, no. 1, pp. 91-100, Jan. 2014.

[24] Payam Alemi and Dong-Choon Lee, “A Generalized Loss Analysis Algorithm of Power Semiconductor Devices in Multilevel NPC Inverters," Journal of Electrical Engineering \& Technology, vol. 9, no. 6, pp. 2168-2180, Aug. 2014.

[25] Y. Shi and X. Yang, "Wide-range soft-switching PWM three-level combined DC-DC converter without added primary clamping devices," IEEE Transactions on Power Electronics, vol. 29, no. 10, pp. 5157-5171, Oct. 2014.

[26] S. Das, G. Narayanan, and M. Pandey, "Space-vectorbased synchronized three-level discontinuous PWM for medium-voltage high-power VSI," vol. 61, no. 8, pp. 3891-3901, Aug. 2014.

[27] P. Chaturvedi, S. Jain and P. Agarwal, "Carrier-Based Neutral Point Voltage Regulator with Reduced Switching Losses for Three-Level Diode-Clamped Inverter," IEEE Transactions on Industrial Electronics, vol. 61, no. 2, pp. 613-624, Feb. 2014.

[28] Y. Jiao, F. C. Lee, and S.Z. Lu, "Space Vector Modulation for Three-Level NPC Converter with Neutral Point Voltage Balance and Switching Loss Reduction," IEEE Transactions on Industrial Electronics, vol. 29, no. 10, pp. 5579-5591, Oct. 2014.

[29] Nam-Joon Ku, Rae-Young Kim and Dong-Seok Hyun, "Partial O-state Clamping PWM Method for 
Three-Level NPC Inverter with a SiC Clamp Diode," Journal of Electrical Engineering \& Technology, vol. 10, no. 3, pp. 1066-1074, Oct. 2015.

[30] G. Carrara, S. Gardella, M. Marchesoni, R. Salutari and G. Sciutto, "A new multilevel PWM method: a theoretical analysis", added primary clamping devices," IEEE Transactions on Power Electronics, vol. 7, no. 3, pp. 497-505, Mar.1992.

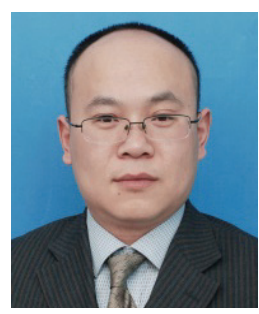

Weidong Jiang (M'15) was born in Sichuan, China, in 1976. He received the B.S. and the Ph.D degree in electrical engineering. from Hefei University of Technology, Hefei, China, in1999 and 2004, respectively. Since June 2004, he has been with the School of Electrical Engineering and Automation, Hefei University of Technology, Hefei, China, where he is currently a Professor. His research interests include electrical machines and their control systems, power electronics, and electric drives. Applications of switching-mode power supplies.

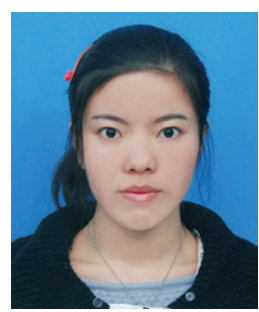

Yan Gao was born in Yancheng, Jiangsu Province, China, in 1993. She received the B.Sc. degree from the Department of Electrical Engineering and Automation, Hefei University of Technology, Hefei, China, in 2015, She is working toward the M.S. degree in the Department of Electrical Engineering, Hefei university of Technology, Hefei, China. Her main research interests include power electronics, and power converters in renewable energy.

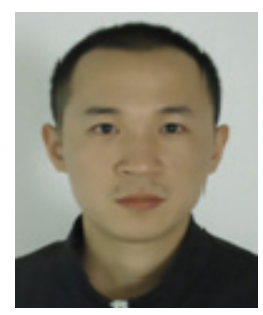

Jinping Wang (M'16) was born in Hunan, China, in 1984. He received the B.S. degree in electronic and information engineering and the Ph.D. degree in electrical engineering from Southwest Jiao tong University, Chengdu, China, in 2007 and 2013. Since June 2013, he has been with the School of Electrical Engineering and Automation, Hefei University of Technology, Hefei, China, where he is currently an Associate Professor. His main research interests include modeling, analysis, control and applications of switching-mode power supplies.

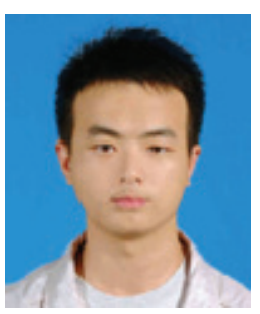

Lei Wang (S'16) was born in Anqing, Anhui Province, China. He received the B.Sc. degree from the Department of Electrical Engineering and Automation, Hefei University of Technology, Hefei, China, in 2014, where he is currently working toward the M.S. degree in the Department of Electrical

Engineering. His research interests include digital control and application of power converters in renewable energy and power quality. 